\title{
CORRIGENDUM
}

\section{Routinization and medicalization of palliative care: Losses, gains and challenges-CORREGENDUM}

\author{
CIRO AUGUSTO FLORIANI M.D., PH.D., AND FERMIN ROLAND SCHRAMM PH.D.
}

(Palliative and Supportive Care (2012), doi:10.1017/S1478951511001039)

At the end of the first two paragraphs in the Introduction section, there are two references missing from the original article, we have added them below:

The "good death" constitutes one - and because of its practical implications perhaps the most important - of the conceptual guidelines for the modern hospice movement. It was the desire to offer marginalized and abandoned patients a peaceful, serene death, with compassionate reception, based on the idea of the "good death," that initially triggered the movement, and the effort to fulfil this doctrine represents a genuine leitmotif for the professionals involved in its daily practice (McNamara et al., 1995; McNamara, 2001; Menezes, 2004). Furthermore, the hospice movement, drawing on its philosophical foundations, presents an argument that aims to legitimize the proposal of a care practice that involves frank communication with the patient as regards the diagnosis, prognosis, and treatment plan, in line with the patient's own wishes, all within the context of an environment of unconditional hospitality (Saunders, 1974; Floriani \& Schramm, 2010a).

However, Clark's question "What is a good death in a world that for many is post-religious and medicalized?" (Clark, 2003, p.174) leads us to reflect on this essential dimension of the hospice movement philosophy. In this regard, for the hospice movement, what would be a "good death?" It has been suggested that this would consist of a set of phenomenal characteristics and practical prerogatives of facing death, which would sustain the possibility of a virtuous and heroic disposition of the dying individual: the kalós thánatos (Kellehear, 1990; Floriani \& Schramm, 2010b).

There was a type error in the first sentence in the third paragraph in section "Charisma versus Routinization in the Modern Hospice Movement," The corrections have been made below:

As Weber observes, however, "it is the fate of charisma, whenever it comes into the permanent institutions of a community, to give way to powers of tradition or of rational socialisation (...) of all those powers that lessen the importance of individual action, the most irresistible is rational discipline [italics in the original]" (Weber, 1982: 292).

\section{REFERENCES}

Floriani, C.A. \& Schramm, F.R. (2010a). How might Levinas' concept of the other's priority and Derrida's unconditional hospitality contribute to the philosophy of the modern hospice movement? Palliative and Supportive Care, 8, $215-220$.

Floriani, C.A. \& Schramm, F.R. (2010b). Journey of struggle: Kalothanasia and the hospice way of dying. Palliative and Supportive Care, 8, 461-468. 